\title{
Nestin is highly expressed in advanced-stage melanomas and neurotized nevi
}

\author{
MICHIKO AKIYAMA $^{1,2}$, YOKO MATSUDA ${ }^{1}$, TOSHIYUKI ISHIWATA ${ }^{1}$, ZENYA NAITO $^{1}$ and SEIJI KAWANA ${ }^{2}$ \\ ${ }^{1}$ Departments of Pathology and Integrative Oncological Pathology, Nippon Medical School, Tokyo 113-8602; \\ ${ }^{2}$ Department of Dermatology, Graduate School of Medicine, Nippon Medical School, Tokyo 113-8603, Japan
}

Received November 28, 2012; Accepted January 4, 2013

DOI: $10.3892 /$ or.2013.2287

\begin{abstract}
Nestin, a class VI intermediate filament protein, was originally described as a neural stem cell/progenitor cell marker. Expression of nestin has been reported to be associated with the migration and metastasis of various types of tumor. In the present study, we examined the expression of nestin in malignant melanomas and nevi. Immunohistochemically, nestin was detected in all compound nevi, but not in the majority of junctional nevi. Nestin was expressed at particularly high levels in nevi with neurotization. In melanoma, nestin was expressed in all T3 and T4 cases, but only in half of the cases of $\mathrm{T} 2$ or less severe disease. These results indicate that the expression levels of nestin in melanoma are associated with advanced disease. In conclusion, nestin was expressed in advanced melanoma tissues and neurotized nevi. Nestin may be an important marker of melanocytic neoplasms. Further studies are required to elucidate the regulatory mechanisms of nestin expression and to examine the possibility of nestintargeted therapy for malignant melanomas.
\end{abstract}

\section{Introduction}

The incidence of malignant melanoma is increasing worldwide (1). Although melanoma accounts for only $4 \%$ of skin cancer cases (2), it accounts for $79 \%$ of skin cancer-related deaths (3). Melanoma can be cured if excised at an early stage. However, once tumors have disseminated to distant organs, systemic chemotherapy induces a complete response in less than $2 \%$ of cases and the median survival time is 9 months (4). Novel therapies were recently approved for advanced melanoma by the US Food and Drug Administration (5), including vemurafenib, a BRAF inhibitor, for patients positive for the BRAFV600E mutation, and ipilimumab, an inhibitor of CTLA-4 (cytotoxic T lymphocyte-associated antigen 4),

Correspondence to: Dr Yoko Matsuda, Departments of Pathology and Integrative Oncological Pathology, Nippon Medical School, 1-1-5 Sendagi, Bunkyo-ku, Tokyo 113-8602, Japan

E-mail:ymazda@nms.ac.jp

Key words: nestin, malignant melanoma, nevi, immunohistochemistry that indirectly activates T-cell mediated antitumor immune responses (6). Furthermore, several drugs targeting specific oncogenes or signaling pathways, including cKIT, NRAS, PI3K and MITF, are now in clinical development (7). Further studies aimed at developing novel therapeutic approaches for melanomas are expected to improve the prognosis of this disease.

Nestin, a class VI intermediate filament protein, was originally described as a neural stem cell marker expressed during the development of the central nervous system (8). Nestin is expressed throughout the dermis in the early embryo, but it is subsequently restricted to the follicular connective tissue sheaths later in development and to hair follicles after birth (9). Nestin-positive hair follicle cells located just above the bulge area can differentiate into various cell types during wound healing $(9,10)$ and can regulate the neovascularization of the dermis in association with the hair growth cycle (11). Thus, nestin-positive cells have been considered to be stem cells of the follicular mesenchyme and nestin has been shown to have an important regulatory role in dermal homeostasis and cutaneous neovasculogenesis (9).

Nestin has also been reported to be present in various neoplasms, including pancreatic cancer $(12,13)$, prostate cancer (14), breast cancer (15), glioblastomas (16), gastrointestinal stromal tumors (17), trichoblastoma (18), trichilemmoma (19), squamous cell carcinoma of the skin (20), angiosarcoma (17), dermatofibrosarcoma $(9,21)$ and malignant melanomas (22). A number of studies have shown that nestin expression in human melanomas correlates with a poor prognosis (17,23-26). Nestin has been reported to be overexpressed in advanced stages of melanoma (25), at the invading front (24) and at sites of melanoma metastases $(22,23,27)$. Furthermore, nestin- and CD133-positive circulating melanoma cells were detected in the peripheral blood of patients with advanced-stage melanoma (28) and the number of nestinpositive circulating melanoma cells was associated with short overall survival time (29). These data indicate that nestin may be significantly involved in the invasion and distant metastasis of melanomas.

We hypothesized that nestin could be a marker of melanocyte immaturity and a novel therapeutic target for melanoma. In this study, we examined nestin expression in melanocytic nevi and at different stages of malignant melanoma in order to evaluate its potential as a marker of melanocytic neoplasms and as a therapeutic target for malignant melanomas. 


\section{Materials and methods}

Materials. The following reagents were used for immunohistochemistry: mouse monoclonal anti-nestin antibody from R\&D Systems, Inc. (Westerville, OH, USA); Histofine Simple Stain MAX PO (M) kits from Nichirei (Tokyo, Japan); and New Silane II and the malinol mounting medium from Mutoh Chemical Co. (Tokyo, Japan). All other chemicals and reagents were purchased from Sigma-Aldrich Corp. (St. Louis, MO, USA).

Patients and tissues. For this study, we used tissues from patients (nevi, $\mathrm{N}=53$; malignant melanomas, $\mathrm{N}=17$ ) who received treatment at the Nippon Medical School Hospital (Bunkyo-ku, Tokyo, Japan) between 2004 and 2012. The melanoma patients comprised 10 men and 7 women whose median age was 68 years (range $42-84$ years). The nevus patients comprised 13 men and 40 women whose median age was 37 years (range 14-71 years). The clinicopathological stage was determined according to the TNM classification system (30). This study was carried out in accordance with the Declaration of Helsinki 2008, and informed consent for the use of melanoma and nevus tissues was obtained from all patients.

Immunohistochemistry. Paraffin-embedded tissue sections ( $3 \mu \mathrm{m})$ were immunostained using Histofine Simple Stain MAX PO (M) kits. Following deparaffinization, endogenous peroxidase activity was blocked by incubating sections with $0.3 \%$ hydrogen peroxide in methanol for $30 \mathrm{~min}$. Sections were then incubated overnight at $4^{\circ} \mathrm{C}$ in the absence (negative controls) or presence of monoclonal anti-nestin antibody (diluted 1:200). Bound antibodies were detected with Histofine kits, using diaminobenzidine-tetrahydrochloride as a chromogen. Immunohistochemically stained tissues were considered positive for nestin expression when staining was noted in the cytoplasm of $>10 \%$ of the cells, regardless of the intensity of staining (13). Two investigators (Michiko Akiyama and Yoko Matsuda) separately evaluated all the specimens in a blinded manner.

In situ hybridization. A 235-bp BamHI-EcoRI cDNA fragment, corresponding to nucleotides 1045-1227 of the human nestin cDNA sequence, was subcloned into the pGEM-T vector and the presence of the insert was confirmed by sequencing. Probes were labeled with DIG-UTP using SP6 or T7 RNA polymerase and the DIG RNA-labeling kit. In situ hybridization was carried out as previously described (13). Tissue sections were deparaffinized and incubated with $0.2 \mathrm{M} \mathrm{HCl}$ for $20 \mathrm{~min}$ at room temperature (RT) and then with $100 \mu \mathrm{g} / \mathrm{ml}$ proteinase $\mathrm{K}$ for $15 \mathrm{~min}$ at $37^{\circ} \mathrm{C}$. The sections were postfixed in phosphate-buffered saline (PBS) containing $4 \%$ paraformaldehyde for $5 \mathrm{~min}$, then incubated twice with PBS containing $2 \mathrm{mg} / \mathrm{ml}$ glycine for $15 \mathrm{~min}$ each and then incubated once with 2X standard saline citrate (SSC) containing $50 \%$ formamide for $1 \mathrm{~h}$, prior to the initiation of the hybridization reaction. Hybridization was carried out in a moist chamber for $16 \mathrm{~h}$ at $42^{\circ} \mathrm{C}$. The sections were then washed sequentially with $2 \mathrm{X}$ SSC for $20 \mathrm{~min}$ at $42^{\circ} \mathrm{C}$ and with $0.2 \mathrm{X} \mathrm{SSC}$ for $20 \mathrm{~min}$ at $42^{\circ} \mathrm{C}$. The DIG nucleic acid detection kit was used for immunological detection. The sections were washed briefly with buffer 1
Table I. Summary of the immunohistochemical analysis of nestin expression in nevi and melanomas.

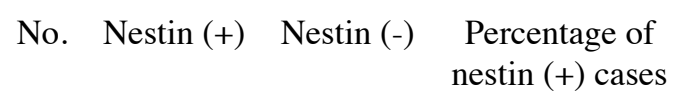

\begin{tabular}{lrrrl}
\hline Nevus & & & & \\
Total & 53 & 31 & 22 & 58.5 \\
Junctional & 26 & 4 & 22 & 15.4 \\
Compound & 27 & $27^{\mathrm{a}}$ & 0 & 100 \\
Melanoma & & & & \\
Total & 17 & 14 & 3 & 82.4 \\
Tis, T1, T2 & 6 & 3 & 3 & 50 \\
T3, T4 & 11 & $11^{\mathrm{a}}$ & 0 & 100 \\
\hline
\end{tabular}

${ }^{\mathrm{a}} \mathrm{P}<0.05$ in the $\chi^{2}$ test.

(100 mM Tris- $\mathrm{HCl}$ and $150 \mathrm{mM} \mathrm{NaCl}, \mathrm{pH} 7.5$ ), incubated with $1 \%(\mathrm{w} / \mathrm{v})$ blocking reagent in buffer 1 for $1 \mathrm{~h}$ at RT and then incubated with alkaline phosphatase-conjugated polyclonal sheep anti-DIG Fab fragment at a 1:2000 dilution for $1 \mathrm{~h}$ at RT. The sections were then washed 3 times with buffer 1 containing $0.2 \%$ Tween-20 for $15 \mathrm{~min}$ at RT, equilibrated in buffer 3 (100 mM Tris- $\mathrm{HCl}, 100 \mathrm{mM} \mathrm{NaCl}$ and $50 \mathrm{mM} \mathrm{MgCl}_{2}, \mathrm{pH} 9.5$ ) for $2 \mathrm{~min}$ and incubated with the staining solution containing nitroblue tetrazolium and X-phosphate in a dark box for 2-3 h. The reaction was stopped by the addition of Tris-EDTA buffer (10 $\mathrm{mM}$ Tris- $\mathrm{HCl}$ and $1 \mathrm{mM}$ EDTA, $\mathrm{pH}$ 8.0) and the sections were mounted in an aqueous mounting medium.

Statistical analysis. All quantitative data are presented as the means \pm SEM. The association of nestin expression levels and clinicopathological features was assessed by the $\chi^{2}$ test. Data for 2 groups were compared using the Student's t-test. $\mathrm{P}<0.05$ was considered to indicate statistically significant differences. Computations were performed using the StatView J version 5.0 (SAS Institute, Inc., Cary, NC, USA).

\section{Results}

Immunohistochemical analysis of nestin in nevi. Immunohistochemical analysis was used to examine the localization of nestin expression in nevi $(\mathrm{N}=53)$. We divided these nevi into 2 groups: junctional, nevus cells located within the epidermis; and compound, nevus cells in the dermis or in both the dermis and epidermis. The junctional nevi consisted of Clark type and the compound nevi consisted of Unna, Miescher and Clark type nevi according to the classification by Ackerman and Magana-Garcia (31). Expression of nestin was detected in all the compound nevi $(\mathrm{N}=27,100 \%)$ and was particularly high in the nevus nest, which showed neural differentiation (Fig. 1A and B), whereas only 4/26 junctional nevi were positive for nestin (15.4\%) (Fig. 1C and D). The $\chi^{2}$ test showed that difference in the percentage of nestin-positive nevi was statistically significant between the compound and junctional types $(\mathrm{P}<0.05)$ (Table I). Thus, nevus cells in the epidermal or superficial dermal area tended to be nestin-negative, whereas nevus cells in the deep dermis were nestin-positive. 


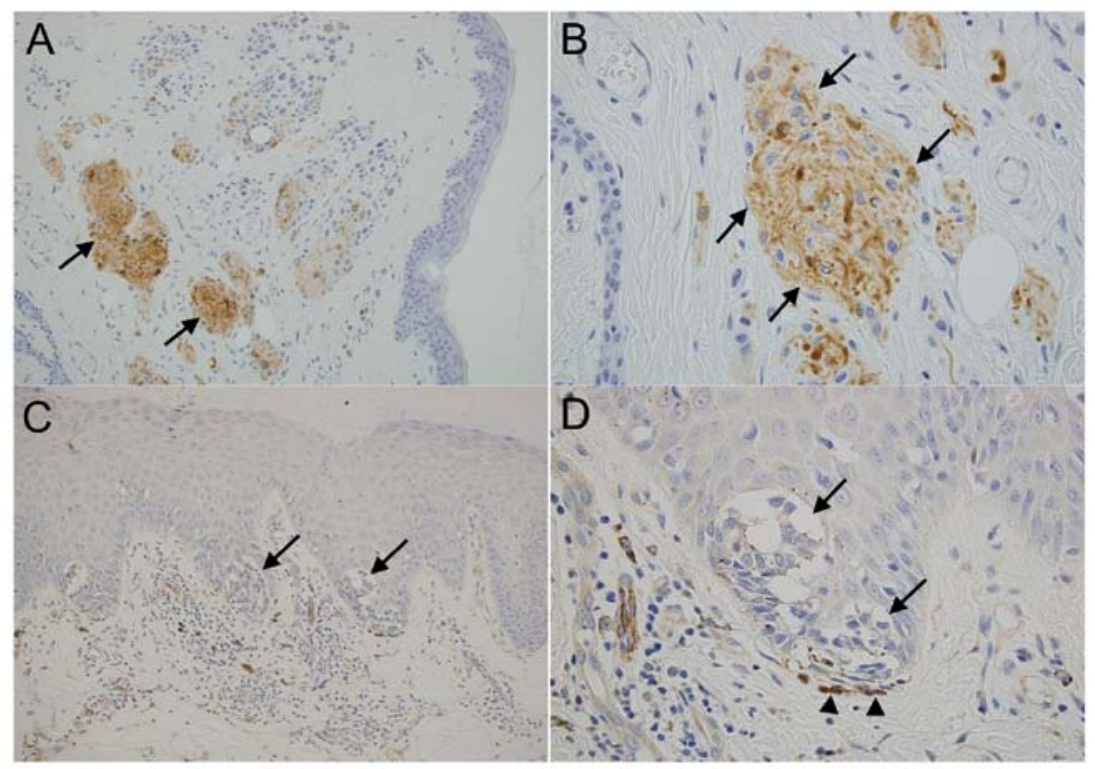

Figure 1. Immunohistochemical analysis of nestin in nevi. (A and B) In Miescher's type of dermal melanocytic nevus, strong expression of nestin was detected in the deep dermal area of nevus nests (arrows). (C and D) In the Clark type of junctional melanocytic nevus, immunoreactivity for nestin was not detected in epidermal nevus nests (arrows). Arrowheads indicate melanin pigments. Original magnification, (A and C) x200, (B and D) x600.

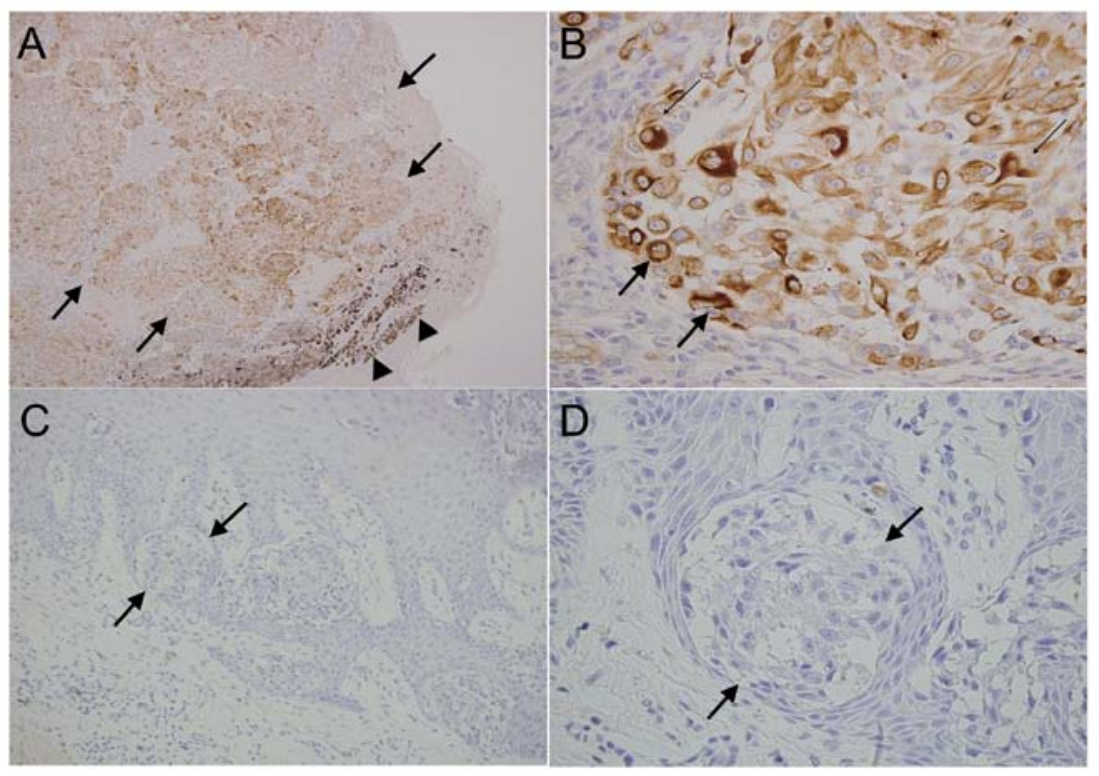

Figure 2. Immunohistochemical analysis of nestin in malignant melanoma. (A and B) In T4 nodular melanoma, dermal tumor cells showed strong expression of nestin (arrows). Melanin pigments are indicated by arrowheads. (C and D) In T2 malignant melanoma, immunoreactivity for nestin was not detected in epidermal melanoma nests (arrows). Original magnification, (A) x100, (C) x200, (B and D) x600.

Immunohistochemical analysis of nestin in malignant melanoma. Immunohistochemical analysis was performed to examine the localization of nestin expression in malignant melanomas $(\mathrm{N}=17)$. Nestin was present in the cytoplasm of tumor cells in 14 of the 17 melanoma cases (82.4\%) (Fig. 2A and $\mathrm{B}$ and Table I). Melanoma cells in epidermal or superficial dermal areas tended to be nestin-negative (Fig. 2C and D), whereas melanoma cells in the deep dermis or thickened melanoma were nestin-positive. Consistent with previous reports, all cases of stage IV $(\mathrm{N}=8,100 \%)$ and stage III melanoma $(\mathrm{N}=3,100 \%)$ were nestin-positive, whereas 2 of the 3 stage II melanoma cases $(66.7 \%)$ and 1 of the 3 stage I and Tis melanoma cases $(33.3 \%)$ were nestin-positive. The $\chi^{2}$ test indicated a statistically significant relationship between melanoma $\mathrm{T}$ stage (Tis-T2 vs. T3-T4) and nestin expression $(\mathrm{P}<0.05)$ (Table I).

Immunohistochemical and in situ hybridization analyses of nestin expression in malignant melanoma. Subsequently, we analyzed serial sections of human melanomas for nestin expression by using in situ hybridization. These experiments revealed that nestin protein and mRNA were strongly expressed in some of the melanoma cells (Fig. 3B and C, arrows). The 


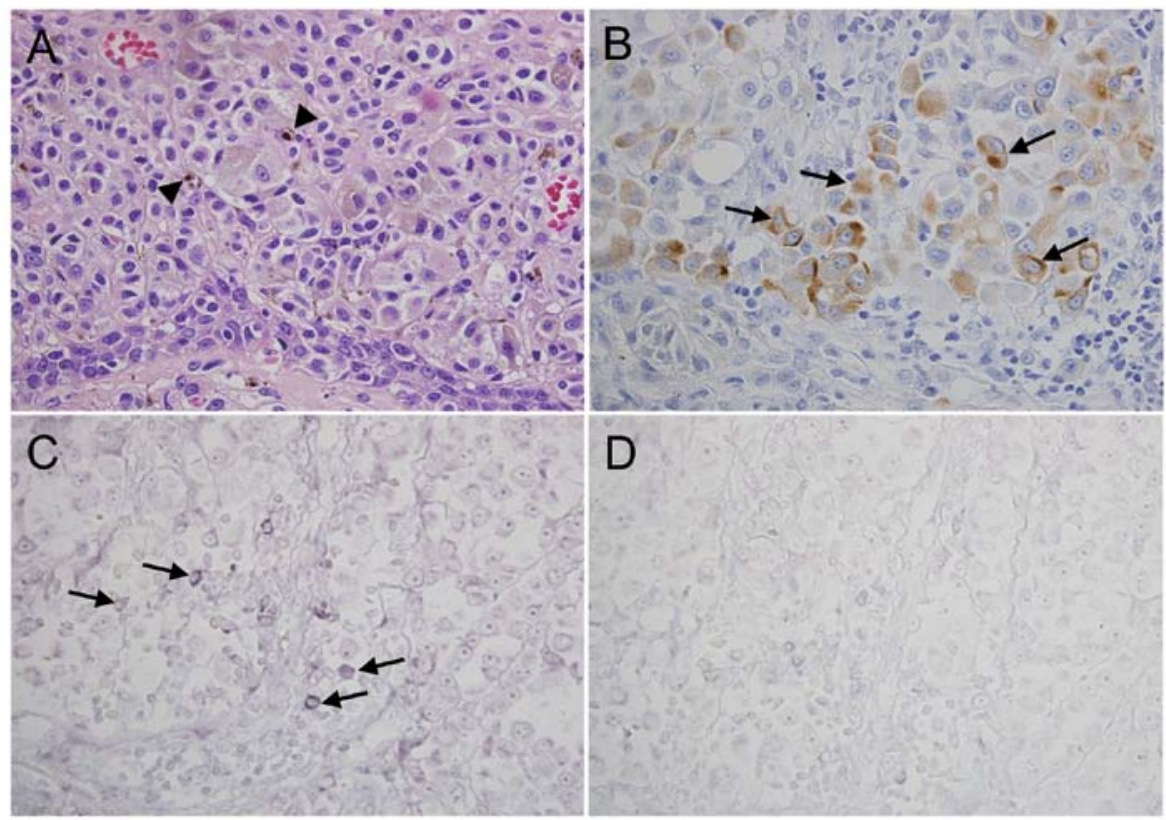

Figure 3. Immunohistochemical and in situ hybridization analyses of nestin in primary cutaneous lesions obtained from a stage IV malignant melanoma patient. (A) Hematoxylin and eosin staining. (B) Immunohistochemical staining of nestin. (C) In situ hybridization using an antisense nestin probe. (D) In situ hybridization using a sense nestin probe. Arrows indicate nestin protein or nestin mRNA. Arrowheads indicate melanin pigment. Original magnification for all panels, $x 600$.

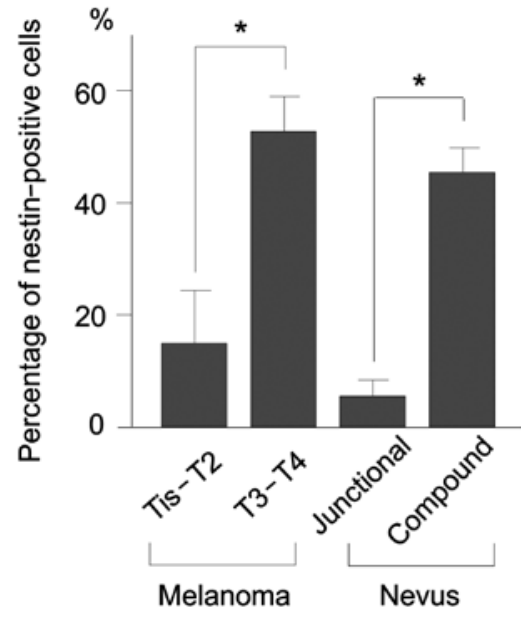

Figure 4. Percentage of nestin-positive cells in melanomas and nevi. Nestin expression was significantly higher in T3-T4 than in Tis-T2 melanomas. Nestin expression was also significantly higher in compound than in junctional nevi. ${ }^{*} \mathrm{P}<0.05$.

control sense probe did not produce a signal (Fig. 3D). Serial sections from 3 additional melanoma tissues were analyzed for nestin expression by using immunohistochemical staining and in situ hybridization and showed similar expression patterns (data not shown).

Percentage of nestin-positive cells in melanomas and nevi. We divided melanoma cases into 2 groups: Tis-T2 and T3-T4. Nestin expression was significantly higher in T3-T4 melanomas, in which tumor thickness is $>2 \mathrm{~mm}$, than in Tis-T2 melanomas, in which tumor thickness is $\leq 2 \mathrm{mM}(\mathrm{P}<0.05)$ (Fig. 4). Nestin expression was also significantly higher in compound than in junctional nevi $(\mathrm{P}<0.05)$ (Fig. 4).

\section{Discussion}

In this study, nestin was expressed in all the compound nevi, which have dermal nests of nevus cells, whereas only a small number of junctional nevi showed nestin expression. Of note, nestin was strongly expressed in the nevus nests in the dermal area that show what is referred to as neurotization (32). Nevus cells are derived from neural crest cells, which give rise to diverse cellular phenotypes, including Schwann, glia and melanocytes (33). It has been suggested that nevi with neuroid changes are transformed from Schwann cells, or, alternatively, may result from a natural regression of nevus cells (32). Thus, the strong nestin expression in neurotized nevus cells may relate to it being a neural stem/progenitor cell marker.

In malignant melanoma, nestin expression was observed in all T3 and T4 melanomas, in which tumor thickness is more than $2 \mathrm{~mm}$, but only in half of the T2, T1 and Tis tumors, in which tumor thickness is $2 \mathrm{~mm}$ or less. This stepwise increase in nestin expression is consistent with previous reports $(23,25,26)$. We also observed strong nestin expression in the peripheral area or invading front of the tumor in some T4 cases, a finding that is in accordance with previous results $(24,25)$.

A critical question that has yet to be clarified is whether, in melanoma tumorigenesis, the cell that initiates melanoma is a cancer stem cell. Herein, we showed that nestin was expressed in both malignant melanomas and nevi, an observation that is significant with respect to the origin and/or behavior of these tumors. Consistent with previous reports, we also showed that the expression of nestin was increased in advanced-stage melanomas (25). The mechanism that underlies this increase remains unknown, but it may be associated with the increase in stem/progenitor-like cells caused by the dedifferentiation of 
melanoma cells or the accumulation of immature phenotype cells observed in patients with advanced-stage melanoma.

In conclusion, nestin was expressed in advanced melanoma tissues and neurotized nevi. Nestin is therefore a potentially important marker of melanocytic neoplasms; however, further studies are required to elucidate the molecular processes that regulate nestin expression and to evaluate the potential of nestin-targeted therapy for malignant melanomas.

\section{Acknowledgements}

The authors thank Ms. Yoko Kawamoto and Ms. Taeko Suzuki (Departments of Pathology and Integrative Oncological Pathology) for their technical assistance and Dr Shin-ichi Tsuchiya (Division of Surgical Pathology, Nippon Medical School Hospital) for preparing tissue blocks. This study was supported by Leave a Nest Co., Ltd., a Grant-in-Aid for Scientific Research (M. Akiyama) and a Grant-in-Aid for Young Scientific Research (A, no. 22689038 to Y. Matsuda).

\section{References}

1. Ferlay J, Shin HR, Bray F, Forman D, Mathers C and Parkin DM: Estimates of worldwide burden of cancer in 2008: GLOBOCAN 2008. Int J Cancer 127: 2893-2917, 2010.

2. Essner R, Belhocine T, Scott AM and Even-Sapir E: Novel imaging techniques in melanoma. Surg Oncol Clin North Am 15: 253-283, 2006

3. Kochhar R, Ali H, Mak S and Manoharan P: Metastatic cutaneous malignant melanoma: spectrum of imaging findings and the role of multimodality imaging. J Med Imaging Radiat Oncol 53: 467-478; quiz 478-479, 2009.

4. Lee ML, Tomsu K and Von Eschen KB: Duration of survival for disseminated malignant melanoma: results of a meta-analysis. Melanoma Res 10: 81-92, 2000.

5. Goozner M: Drug approvals 2011: focus on companion diagnostics. J Natl Cancer Inst 104: 84-86, 2012.

6. Finn L, Markovic SN and Joseph RW: Therapy for metastatic melanoma: the past, present and future. BMC Med 10: 23, 2012.

7. Flaherty KT and Fisher DE: New strategies in metastatic melanoma: oncogene-defined taxonomy leads to therapeutic advances. Clin Cancer Res 17: 4922-4928, 2011.

8. Lendahl U, Zimmerman LB and McKay RD: CNS stem cells express a new class of intermediate filament protein. Cell 60: 585-595, 1990.

9. Sellheyer K and Krahl D: Spatiotemporal expression pattern of neuroepithelial stem cell marker nestin suggests a role in dermal homeostasis, neovasculogenesis and tumor stroma development: a study on embryonic and adult human skin. J Am Acad Dermatol 63: 93-113, 2010.

10. Amoh Y, Kanoh M, Niiyama S, et al: Human and mouse hair follicles contain both multipotent and monopotent stem cells. Cell Cycle 8: 176-177, 2009.

11. Amoh Y, Li L, Yang M, et al: Nascent blood vessels in the skin arise from nestin-expressing hair-follicle cells. Proc Natl Acad Sci USA 101: 13291-13295, 2004.

12. Matsuda Y, Naito Z, Kawahara K, Nakazawa N, Korc M and Ishiwata T: Nestin is a novel target for suppressing pancreatic cancer cell migration, invasion and metastasis. Cancer Biol Ther 11: 512-523, 2011.
13. Kawamoto M, Ishiwata T, Cho K, et al: Nestin expression correlates with nerve and retroperitoneal tissue invasion in pancreatic cancer. Hum Pathol 40: 189-198, 2009.

14. Kleeberger W, Bova GS, Nielsen ME, et al: Roles for the stem cell associated intermediate filament Nestin in prostate cancer migration and metastasis. Cancer Res 67: 9199-9206, 2007.

15. Li H, Cherukuri P, Li N, et al: Nestin is expressed in the basal/ myoepithelial layer of the mammary gland and is a selective marker of basal epithelial breast tumors. Cancer Res 67: 501-510, 2007.

16. Ishiwata T, Teduka K, Yamamoto T, Kawahara K, Matsuda Y and Naito Z: Neuroepithelial stem cell marker nestin regulates the migration, invasion and growth of human gliomas. Oncol Rep 26: 91-99, 2011.

17. Yang XH, Wu QL, Yu XB, et al: Nestin expression in different tumours and its relevance to malignant grade. J Clin Pathol 61: 467-473, 2008.

18. Misago N, Mori T and Narisawa Y: Nestin expression in stromal cells of trichoblastoma and basal cell carcinoma. J Eur Acad Dermatol Venereol 24: 1354-1358, 2010.

19. Kanoh M, Amoh Y, Tanabe K, Maejima H, Takasu H and Katsuoka K: Nestin is expressed in HMB-45 negative melanoma cells in dermal parts of nodular melanoma. J Dermatol 37: 505-511, 2010.

20. Abbas O and Bhawan J: Expression of stem cell markers nestin and cytokeratin 15 and 19 in cutaneous malignancies. J Eur Acad Dermatol Venereol 25: 311-316, 2011.

21. Mori T, Misago N, Yamamoto O, Toda S and Narisawa Y: Expression of nestin in dermatofibrosarcoma protuberans in comparison to dermatofibroma. J Dermatol 35: 419-425, 2008.

22. Florenes VA, Holm R, Myklebost O, Lendahl U and Fodstad O: Expression of the neuroectodermal intermediate filament nestin in human melanomas. Cancer Res 54: 354-356, 1994.

23. Klein WM, Wu BP, Zhao S, Wu H, Klein-Szanto AJ and Tahan SR: Increased expression of stem cell markers in malignant melanoma. Mod Pathol 20: 102-107, 2007.

24. Piras F, Perra MT, Murtas D, et al: The stem cell marker nestin predicts poor prognosis in human melanoma. Oncol Rep 23: $17-24,2010$

25. Brychtova S, Fiuraskova M, Hlobilkova A, Brychta T and Hirnak J: Nestin expression in cutaneous melanomas and melanocytic nevi. J Cutan Pathol 34: 370-375, 2007.

26. Tanabe K, Amoh Y, Kanoh M, et al: Prognostic significance of the hair follicle stem cell marker nestin in patients with malignant melanoma. Eur J Dermatol 20: 283-288, 2010.

27. Mihic-Probst D, Kuster A, Kilgus S, et al: Consistent expression of the stem cell renewal factor BMI-1 in primary and metastatic melanoma. Int J Cancer 121: 1764-1770, 2007.

28. Fusi A, Ochsenreither S, Busse A, Rietz A and Keilholz U: Expression of the stem cell marker nestin in peripheral blood of patients with melanoma. Br J Dermatol 163: 107-114, 2010.

29. Fusi A, Reichelt U, Busse A, et al: Expression of the stem cell markers nestin and CD133 on circulating melanoma cells. J Invest Dermatol 131: 487-494, 2011.

30. Balch CM, Gershenwald JE, Soong SJ, et al: Final version of 2009 AJCC melanoma staging and classification. J Clin Oncol 27: 6199-6206, 2009.

31. Ackerman AB and Magana-Garcia M: Naming acquired melanocytic nevi. Unna's, Miescher's, Spitz's Clark's. Am J Dermatopathol 12: 193-209, 1990.

32. Van Paesschen MA, Goovaerts G and Buyssens N: A study of the so-called neurotization of nevi. Am J Dermatopathol 12: 242-248, 1990 .

33. Misago N: The relationship between melanocytes and peripheral nerve sheath cells (Part I): melanocytic nevus (excluding so-called 'blue nevus') with peripheral nerve sheath differentiation. Am J Dermatopathol 22: 217-229, 2000. 